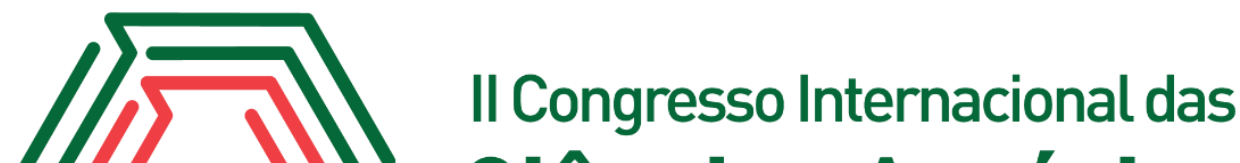 Ciências Agrárias COINTER - PDVAgro 2017
}

\section{PRODUÇÃO DE DIFERENTES CULTIVARES DE CENOURA}

\author{
Apresentação: Pôster
}

\begin{abstract}
Antonio Gideilson Correia da Silva ${ }^{1}$; Joabe Freitas Crispim²; José Elinaldo Alves Bento ${ }^{3}$; Jacquelinne Alves de Medeiros Araújo ${ }^{4}$; Jailma Suerda Silva de Lima ${ }^{5}$
\end{abstract}

\section{Introdução}

A cenoura (Daucus carota L) é uma hortaliça da família Apiaceae, tem como parte comestível a raiz tuberosa de cor alaranjada. Esta tem grande destaque pelo seu valor nutritivo, sendo fonte do precursor da vitamina A (Beta-caroteno), e de outras substâncias que ajudam a prevenir e proteger contra o câncer e a cegueira.

A preferência do consumidor brasileiro é por raízes de cenoura bem desenvolvidas, cilíndricas, lisas, sem raízes laterais ou secundárias, uniformes, com comprimento variando entre quinze e vinte $\mathrm{cm}$ e com diâmetro de 3 a $4 \mathrm{~cm}$. A coloração deve ser alaranjada intensa, com ausência de ombro (parte superior das raízes) com pigmentação verde ou roxa (VIEIRA et al., 1999).

Os principais estados produtores de cenoura são Minas Gerais, Bahia, Paraná e São Paulo. Destaca-se como maior produtor nacional o estado de Minas Gerais, com três importantes pólos de produção de cenoura. O principal desses pólos é a região de Rio Paranaíba (São Gotardo, Rio Paranaíba, Campos Altos, Tiros, Ibiá, Matutina) que, em uma área de 8 mil hectares e com produtividade média de $35 \mathrm{t} \mathrm{ha}^{-1}$, vem respondendo por mais de $37 \%$ da produção nacional (EMATER-MG, 2007).

As empresas produtoras lançam sempre no mercado novas cultivares de cenoura e com ampla adaptação as diferentes condições climáticas. Cultivares como a Brasília, Alvorada, Esplanada e Suprema possuem uma resistência ao calor fazendo com que seja mais fácil a produção dessas

\footnotetext{
${ }^{1}$ Agronomia, UFERSA, antoniogideilson@hotmail.com

${ }^{2}$ Agronomia, UFERSA, crispinjoabef@gmail.com

${ }^{3}$ Agronomia, UFERSA, elinaldoalves.lavras@gmail.com

${ }^{4}$ Agronomia, UFERSA, jacquelinne87@hotmail.com

${ }^{5}$ Doutora, UFERSA, jailmaagro@gmail.com
} 
cultivares em regiões de alta temperatura, além de possuírem outras características similares como a resistência a queima-das-folhas e tendo um ponto de colheita próximo, em torno de 90 a 100 dias após a semeadura.

O objetivo deste trabalho foi avaliar o desempenho produtivo de quatro cultivares de cenoura (Brasília, Alvorada, Esplanada e Suprema).

\section{Fundamentação Teórica}

Este experimento tende a esclarecer qual cultivarde cenoura commaior adaptabilidade a região de Mossoró, usando 4 variedade de cenoura (Brasília, Alvorada, Esplanada e Suprema), essas cultivares apresentam características de resistência ao calor,apresentando baixos níveis de florescimento prematuro no verão, além de terem um ciclo semelhantes. Espera-se destaque na produtividade comercial de cada uma dessas cultivares a base de húmus bovino.

Oliveira et al. (2001), ao estudar o efeito da adubação com húmus de minhoca na produção de raízes de cenoura cultivadas obtiveram, $17 \mathrm{t}$ ha- ${ }^{-1} ; 44,3$ t ha-1 $\mathrm{e} 61,3 \mathrm{t}$ ha- ${ }^{1}$ para produção comercial, não comercial e total de raízes de cenoura, respectivamente. Espera-se recomendar a melhor das cultivares de cenoura, adubadas com húmus bovino

\section{Metodologia}

O experimento foi conduzido na fazenda experimental Rafael Fernandes, no período de junho a setembro de 2017. O delineamento experimental utilizado foi o de blocos completos casualizados, com quatro cultivares e quatro repetições. Os tratamentos consistiram de quatro cultivares (Brasília, Alvorada, Esplanada e Suprema). A área total da parcela foi 1,44m² $(1,20 \mathrm{~m} x$ $1,20 \mathrm{~m})$, com uma área útil de $0,80 \mathrm{~m}^{2}$.

Foi realizada uma solarização em pré-plantio durante 45 dias para desinfestação de organismos fitopatógenos passíveis de causar danos à cultura.

O adubo utilizado foi o húmus à base de esterco bovino, adquirido em Catolé do Rocha-PB, onde se utilizou $3,60 \mathrm{~kg} / \mathrm{m}^{2}$ que foi incorporado ao solo 5 dias antes do plantio.

A semeadura foi diretamente em covas. O desbaste foi realizado aos dez dias após o plantio, deixando-se uma planta por cova. A cultura foi irrigada pelo sistema de micro-aspersão, com turno de rega diário parcelado em duas aplicações (manhã e tarde). Foi realizado a amontoa na cultura a fim de proteger as raízes e evitar o aspecto esverdeado característico. Durante a condução do 
experimento, foram realizadas capinas manuais sempre que necessário. A colheita foi realizada aos 61 dias após o plantio.

As características avaliadas na cenoura foram: altura de plantas numa amostra de 20 plantas ,número de folhas, massa seca e massa fresca da parte aérea e da raiz, que foram analisadas em uma amostra de 20 plantas aleatoriamente escolhidas, a massa fresca da parte aérea e da raiz foi pesada numa balança, após isso foi levada pra uma estufa onde passou do dia 1 de outubro de 2017 ate o dia 10 de outubro de 2017, logo após foi feito o peso da massa seca da parte aérea e da raiz. Produção total e comercial e produção classificada de raízes (raízes refugo, curtas, médias e longas). A produtividade total e comercial e a produtividade de raízes refugo da cenoura serão obtidas a partir da massa fresca das raízes da área útil da parcela, expressas em $\mathrm{t} \mathrm{ha}^{-1}$. Considera-se como produtividade comercial as raízes livres de defeitos como, rachaduras, bifurcações, nematóides e danos mecânicos. A produtividade classificada de raízes é obtida segundo o comprimento e maior diâmetro transversal em: longas (comprimento de 17 a $25 \mathrm{~cm}$ e diâmetro menor que $5 \mathrm{~cm}$ ), médias (comprimento de 12 a $17 \mathrm{~cm}$ e diâmetro maior que 2,5 cm), curtas (comprimento de 5 a $12 \mathrm{~cm}$ e diâmetro maior que $1 \mathrm{~cm}$ ) e refugo (raízes que não se enquadram nas medidas anteriores), conforme Lana e Vieira (2000). O teste de Tukey a 5\% foi utilizado para comparar as médias entre as cultivares avaliadas.

\section{Resultados e Discussões}

Não foram observadas diferenças significativas entre as cultivares para nenhuma das características analisadas para todas as características avaliadas (Tabela 1 e Tabela 2).

Tabela 1. Altura de plantas (AP), número de folhas (NF), massa fresca (MFPA) e seca da parte aérea (MSPA) e massa seca de raiz (MSR) de cenoura em função de cultivares de cenoura. Fonte própria

\begin{tabular}{cccccc}
\hline Cultivares & AP & NF & MFPA & MSPA & MSR \\
\hline Brasília & $35,17 \mathrm{a}$ & $9,90 \mathrm{a}$ & $0,59 \mathrm{a}$ & $4,00 \mathrm{a}$ & $4,79 \mathrm{a}$ \\
Alvorada & $33,64 \mathrm{a}$ & $9,36 \mathrm{a}$ & $0,54 \mathrm{a}$ & $3,78 \mathrm{a}$ & $4,54 \mathrm{a}$ \\
Esplanada & $35,50 \mathrm{a}$ & $9,79 \mathrm{a}$ & $0,49 \mathrm{a}$ & $3,50 \mathrm{a}$ & $4,48 \mathrm{a}$ \\
Suprema & $36.99 \mathrm{a}$ & $9,69 \mathrm{a}$ & $0,60 \mathrm{a}$ & $4,18 \mathrm{a}$ & $4,65 \mathrm{a}$ \\
\hline
\end{tabular}

* Médias seguidas pelas mesmas letras minúsculas na linha não diferem entre si pelo teste de Tukey ao nível de 5\% de probabilidade.

Apesar das cultivares não apresentarem diferenças estatísticas significativas, pode se perceber que a cultivar Brasília apresentou maior média com relação a número de folhas, massa 
seca da raiz e massa fresca da parte aérea. Já a cultivar Suprema teve maior média nas características de altura de planta e da massa seca da parte aérea.

Tabela 2. Produtividade classificada em longas (LONG), médias (MED), curta (CURT) e refugo (REF), produtividade total(PT) e produtividade comercial (PC) de raízes em função de cultivares de cenoura Fonte: Própria.

\begin{tabular}{lllllll}
\hline Cultivares & LONG & MED & CURT & REF & PT & PC \\
\hline Brasília & $8,13 \mathrm{a}$ & $8,02 \mathrm{a}$ & $1,63 \mathrm{a}$ & $0,65 \mathrm{a}$ & $18,42 \mathrm{a}$ & $17,78 \mathrm{a}$ \\
Alvorada & $2,26 \mathrm{a}$ & $8,75 \mathrm{a}$ & $2,32 \mathrm{a}$ & $0,68 \mathrm{a}$ & $14,00 \mathrm{a}$ & $13,33 \mathrm{a}$ \\
Esplanada & $4,38 \mathrm{a}$ & $8,42 \mathrm{a}$ & $1,21 \mathrm{a}$ & $0,22 \mathrm{a}$ & $14,22 \mathrm{a}$ & $14,00 \mathrm{a}$ \\
Suprema & $5,30 \mathrm{a}$ & $7,47 \mathrm{a}$ & $1,93 \mathrm{a}$ & $0,92 \mathrm{a}$ & $15,63 \mathrm{a}$ & $14,70 \mathrm{a}$ \\
\hline
\end{tabular}

* Médias seguidas pelas mesmas letras minúsculas na linha não diferem entre si pelo teste de Tukey ao nível de 5\% de probabilidade.

Apesar das cultivares não apresentarem diferenças estatísticas significativas, pode se perceber que a cultivar Brasília apresentou a maior média com relação a produtividade de raízes longas, já a cultivas Alvorada teve a menor média de raízes longas, mais teve maior média com relação a raízes de classificação média e curtas, a cultivar Suprema teve maior média com relação a refugos. Na produção total (PT) e produção comercial (PC) a cultivar Brasília apresentou a maior média numericamente em ambas as características analisadas.

Oliveira et al. (2001) ao estudar o efeito da produção de raízes de cenoura cultivadas com húmus de minhoca obtiveram na produção total a média de 70.1 com uma dosagem de húmus 25 ( $\mathrm{t} / \mathrm{ha}$ ), sendo a maior média feita pelo teste de Tukey, apresentando uma média maior do que a vista nesse trabalho, isso pode se dá pelo fato de o referido autor ter usado a adubação mineral no cultivo da cultivar de cenoura.

\section{Conclusões}

A cultivar Brasília teve a maior média de produção total e comercial, sendo numericamente superior as demais cultivares utilizadas.

\section{Referências}

EMATER-MG. Produção e área de hortaliças em Minas Gerais. Belo Horizonte, 2007. (Planilha eletrônica recebida em 17 abril de 2007).

GERALDO MILANEZ DE RESENDE; JONY EISHI YURI; NIVALDO DUARTE COSTA. Desempenho Agronômico de Cultivares de Cenoura no Verão em Sistema Orgânico no Vale do São Francisco.

LANA MM; VIEIRA J V. 2000. Fisiologia e manuseio pós-colheita de cenoura. EMBRAPA CNPH, Circular Técnica 21: 15. 
Miguel Lancho Jiménez.http://blog.mundohorta.com.br/adubacao-plantas-agricultura-organica/

OLIVEIRA, A.P.; ESPÍNOLA, F.E.J.; ARAÚJO, J.S.; COSTA, C.C. Produção de raízes de cenoura cultivadas com húmus de minhoca e adubo mineral. Horticultura Brasileira, Brasília, v. 19, n. 1, p. 77 - 80, março 2.001 